\title{
Gas Sensor Array for Low-cost Gas Chromatography in Food Industry Processes
}

\author{
Marie-Luise Bauersfeld, Carolin Peter, Jürgen Wöllenstein \\ Fraunhofer-Institute for Physical Measurement Techniques IPM \\ Heidenhofstrasse 8, 79110 Freiburg, Germany \\ Mark Bücking, Jörg Bruckert, Jürgen Steinhanses \\ Fraunhofer-Institute for Molecular Biology and Applied Ecology IME \\ Auf dem Aberg 1, 57392 Schmallenberg-Grafschaft, Germany
}

\begin{abstract}
A portable low-cost gas chromatographic measurement system will be presented. The system consists of a novel chromatographic column - which enables measurements at room temperature and ambient air with a downstream micro machined gas sensor array and offers the separation and identification of volatile organic compounds. The targeted application is the monitoring of flavours directly during food processes. The measurement system was characterized by using flavours like methyl pyrrole, hexanal, pinene, ethyl butyrate and limonene as well as ethylene and methyl mercaptan as test gases. Reliable and reproducible identification of the gases in the concentration range of a few ppb has been achieved.
\end{abstract}

\section{Introduction}

Today, food quality plays a more and more significant role for the consumer. Therefore fast monitoring of food quality in the industry gets more important. To protect consumers and always ensure the optimum grade of quality, critical steps during production have to be controlled, to recognise and eliminate failures. Till this day more than 6000 volatile compounds are known which create the aroma of food [1]. Nowadays a multiplicity of aroma characterization methods exists. These are on one hand human sensory test methods and on the other hand analytical methods like gas chromatography (GC) with coupled odorimetry (GC/O) and / or mass spectrometry (GC/MS). Conventional analytical methods are mostly complex, expensive and some volatile compounds are not so good separable by gas chromatograph as per human sense of smell.

The judging of aromas is objective by human. Because of that there are tests to describe flavours by socalled "electronic noses" [2]. This should offer a sensory fingerprint of each aroma by pattern recognition. But the development of those systems for special applications need mostly an especially requirement on qualification of able sensor elements and those calibration [3]. In the past decade, activities directed towards development of low cost chromatographic measurement system using metal oxide gas sensors as detectors have increased substantially. A development so-called HRGC/SOMSA-method (high resolution gas chromatography/selective odorant measurement by multi sensor array) consists of gas chromatographic column and sensor array. On this base exists research for controlled food quality [4, 5, 6]. However, a continuing drawback of such implementations has been the incompatibility of the chromatographic column with ambient air.

Novel chromatographic columns allow measurements at room temperature and ambient air and enable the use of low cost semiconductor gas sensors as detector unit in the gas chromatographic system (Fig. 1). Furthermore the combination of different sensors in a single array offers the possibility to detect aromatic flavours which are, due to their similar chemical behaviour, not separable by the used chromatographic column over time. 


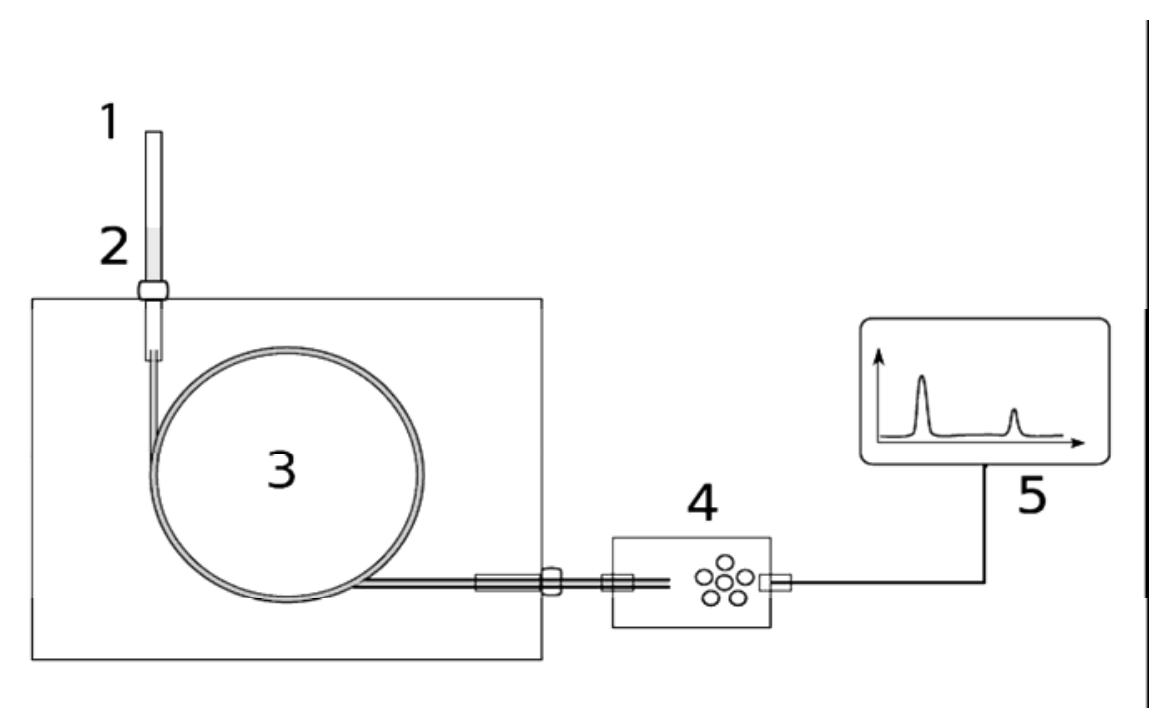

Figure 1 Schematic diagram of the portable low-cost gas chromatographic measurement system. 1 sampling, 2 drying agent, 3 GC column, 4 gas sensor array, 5 data evaluation.

\section{Set Up of Measurement System}

The functionality of the present measurement system for detection of special aromatic compounds, which are released during food processing, based on combination of gas chromatography with downstream micro machined gas sensor array. The single components are described in this part.

\section{A. Gas Sensor Array}

Flavours are volatile gas mixtures, which can be chromatographically separated. Due to their similar chemical behaviour many flavours are not resoluble about the retention time. For the detection of these compounds commercial gas sensors as well as self produced sensors have been tested. The goal of development was that a gas sensor array composes a well-defined fingerprint for each aromatic compound of a gas mixture by different reactions of gas sensor types. The used self produced gas sensor array is fabricated on one chip and consists of four independent semiconductor gas sensors with metallic oxide. To increase the selectivity of every sensor those are manufactured with different gas sensitive layer like tin oxide $\left(\mathrm{SnO}_{2}\right)$, tungsten trioxide $\left(\mathrm{WO}_{3}\right), \mathrm{SnO}_{2}$ with Platinum as catalyst and chromium titanium oxide $\left(\mathrm{Cr}_{2-x} \mathrm{Ti}_{x} \mathrm{O}_{3+z}, \mathrm{CTO}\right)$ [7]. The goal of technological development is the optimizing of these sensors in respect of sensitivity, selectivity and long time stability. Another important parameter is the operating temperature which influences the sensitivity of the sensors. The optimal operating temperature was validated for every using flavour.

\section{B. GC Column}

In addition to gas sensor array the choice of chromatographic column influences the possibilities of measurement system. For gas sensors as detector in this unit it is necessary to use oxygen. But until today many columns are destroyed by oxygen due to use of polymers. A novel commercial available column enables the use of oxygen and an optimal chromatographic separation at $40^{\circ} \mathrm{C}$.

\section{Sampling Supply}

Conventional gas chromatographic systems use an injection into the column for sampling supply. For the target portable system is this option not practicable. In this case a special pump controlled suction mechanism is used. The sampling supply occurs in a sampling loop, which is split in a supply with flushing gas and in a supply with the test gas respectively.

For the first labour tests fluid flavours was evaporated and afterwards according to requirements mixed. For that a defined air stream is managed over the fluid sample to concentrate with vapour phase of flavour [8]. The flavour concentration depends on the temperature of the fluid. The resulting flow with a speed of $150 \mathrm{ml} / \mathrm{min}$ is routed as carrier gas stream into the column and arrives at the measurement chamber with gas sensor array. 


\section{Tested Gases}

Aromatic compounds and gases which are important for later applications - in food chain management of this measurement system were chosen. Special attention is the combination of two flavours which are not separable by the retention period through the chromatographic column. On the base of this the functionality of the gas sensor array as detector and for the differentiation of flavours is demonstrated. Flavours which enclosed direct in fruit and secondary flavours which result of production are chosen. The tested flavours like methyl pyrrole, ethyl butyrate, pinene, limonene and hexanal as well as ethylene and methyl mercaptan including a short description of natural existence and possible applications are display in table 1.

Table $1 \quad$ Tested Aromatic Compounds and Gases

\begin{tabular}{|l|l|l|}
\hline Aroma & Natural existence & Application \\
\hline Methyl pyrrole & result from roasting processing & $\begin{array}{l}\text { monitoring of roasting processing, } \\
\text { e.g. coffee }\end{array}$ \\
\hline Ethyl butyrate & apple & degree of ripeness of fruits \\
\hline a-Pinene & $\begin{array}{l}\text { spruce needle, coriander, } \\
\text { caraway }\end{array}$ & $\begin{array}{l}\text { add in medicaments and essential } \\
\text { oil }\end{array}$ \\
\hline Limonene & citrus fruits & degree of ripeness of fruits \\
\hline Hexanale & $\begin{array}{l}\text { result from decomposition of } \\
\text { fatty acids }\end{array}$ & manufacturing process of nuts \\
\hline Ethylene & $\begin{array}{l}\text { biological hormone in fruits and } \\
\text { vegetables }\end{array}$ & degree of ripeness of fruits \\
\hline Methyl mercaptane & $\begin{array}{l}\text { result from bacterial } \\
\text { degradation of proteins }\end{array}$ & detection of perishable food \\
\hline
\end{tabular}

\section{Results of Measurement}

The descriped measurements are done with labour set up. The sampling supply takes place an admixture of flavours in carrier gas stream of synthetic air. Synthetic air is also use as flushing gas. The sensor chamber has a volume of $4 \mathrm{ml}$, which means a 37 fold gas change per minute for a carrier gas flow of $150 \mathrm{ml} / \mathrm{min}$. Through the operating temperature of gas sensors between $300^{\circ} \mathrm{C}$ for $\mathrm{WO}_{3}$ and $\mathrm{SnO}_{2}$ with $\mathrm{Pt}$ and $450^{\circ} \mathrm{C}$ for $\mathrm{CTO}$ and $\mathrm{SnO}_{2}$ the chamber heated up and adhesion on chamber wall are insignificant. During the measurement the flavour concentrations in table 2 are tested. These are generated by a gas generator [8].

Table $2 \quad$ Tested Flavour and Gas Concentrations

\begin{tabular}{|l|l|}
\hline Gases & Concentration [ppb] \\
\hline Methyl pyrrole & 720 \\
\hline Ethyl butyrate & 399 \\
\hline$\alpha-P i n e n e$ & 66 \\
\hline Ethylene & 50 \\
\hline Limonene & 22 \\
\hline
\end{tabular}

To demonstrate the differentiation of flavours through the developed gas sensor array the first step was to measure with pure flavours. A calculated Principal Components Analysis is present in figure 2. This gives the proof that the measurement of each flavour is discriminable and that the use of the develop gas sensor array enable the separation of the tested flavours. In the figure it is describe that each measuring point is a well-defined point in the scatter plot of the coordinate system. In addition the plot shows that more than one principal component is, for the differentiation of the flavours, necessary. Through both principal components the flavours are graphical separable. Together they safe $96.52 \%$ information of all measurements. 


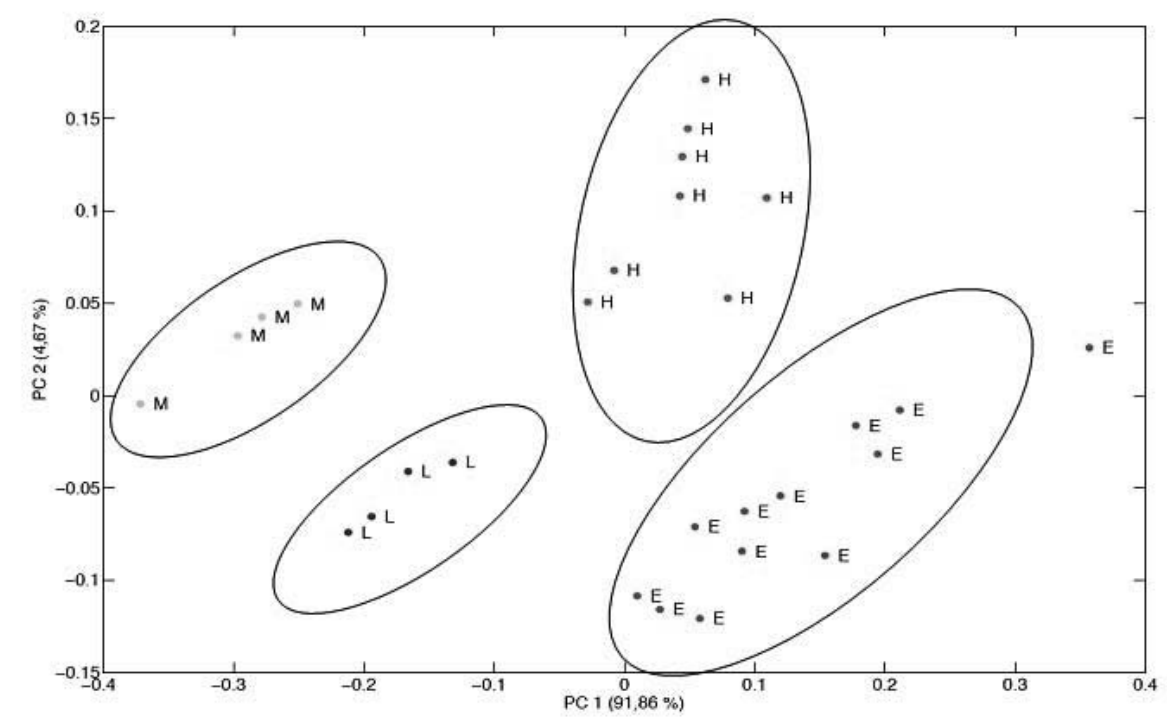

Figure 2 Principal Components Analysis of the analysed flavours (Scores Plot). H: hexanale, E: ethyl butyrate, M: methyl pyrrole, L: limonene. Out of these four, ethyl butyrate and hexanale are not separable over time by a chromatographic column.

An important factor of a gas chromatographic system is the repeatability. In figure 3 the repeat of two measurements is presented. The upper graph shows the sensor reaction of a $\mathrm{SnO}_{2}$ sensor and the lower graph of a CTO sensor. Both are manufactured by Fraunhofer IPM. Notable is that in the measurement with the CTO sensor the transition point between methyl pyrrole and ethyl butyrate is visible (Fig. 4).
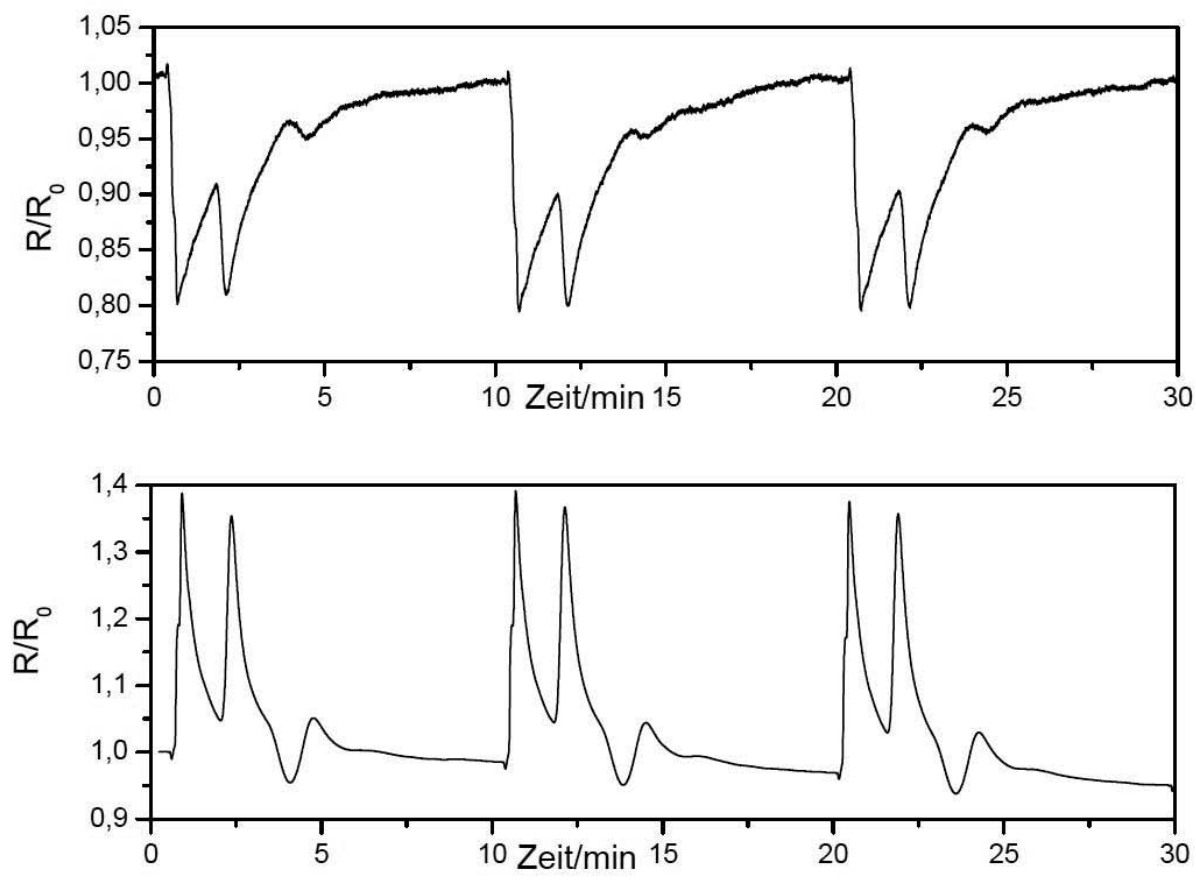

Figure 3 Chromatogram: Reaction of (up) IPM $\mathrm{SnO}_{2}$ and (down) IPM CTO gas sensor to gas mixture which is separate over time by used chromatographic column and as a function of the nominal resistance. The measurement was repeated thrice. The first peak is a mixture from methyl pyrrole and ethyl butyrate and the second peak is $\alpha$-pinene. After $4 \mathrm{~min}$ is the limonene impact. The operating temperature of both sensors is $450^{\circ} \mathrm{C}$. 


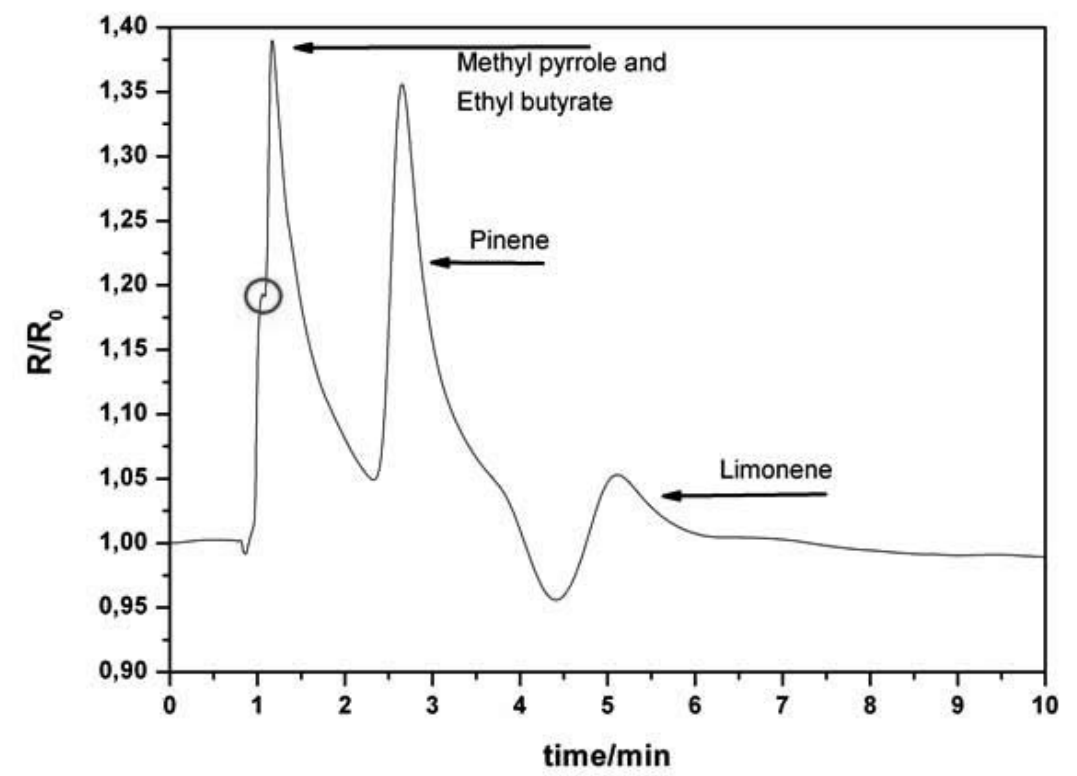

Figure $4 \quad$ Response of IPM gas sensor based on Chromium Titanium Oxide as sensitive layer to different flavours. The marked area signalises the change from methyl pyrrol to ethyl butyrate. The operation temperature during the measurement was $450^{\circ} \mathrm{C}$.

Figure 5 illustrates the comparison between commercial gas sensors as well as self produced sensors and various aroma concentrations. In this figure the significant different response of the represented gas sensors, which can use for well-defined fingerprint of each aromatic compound, is shown.

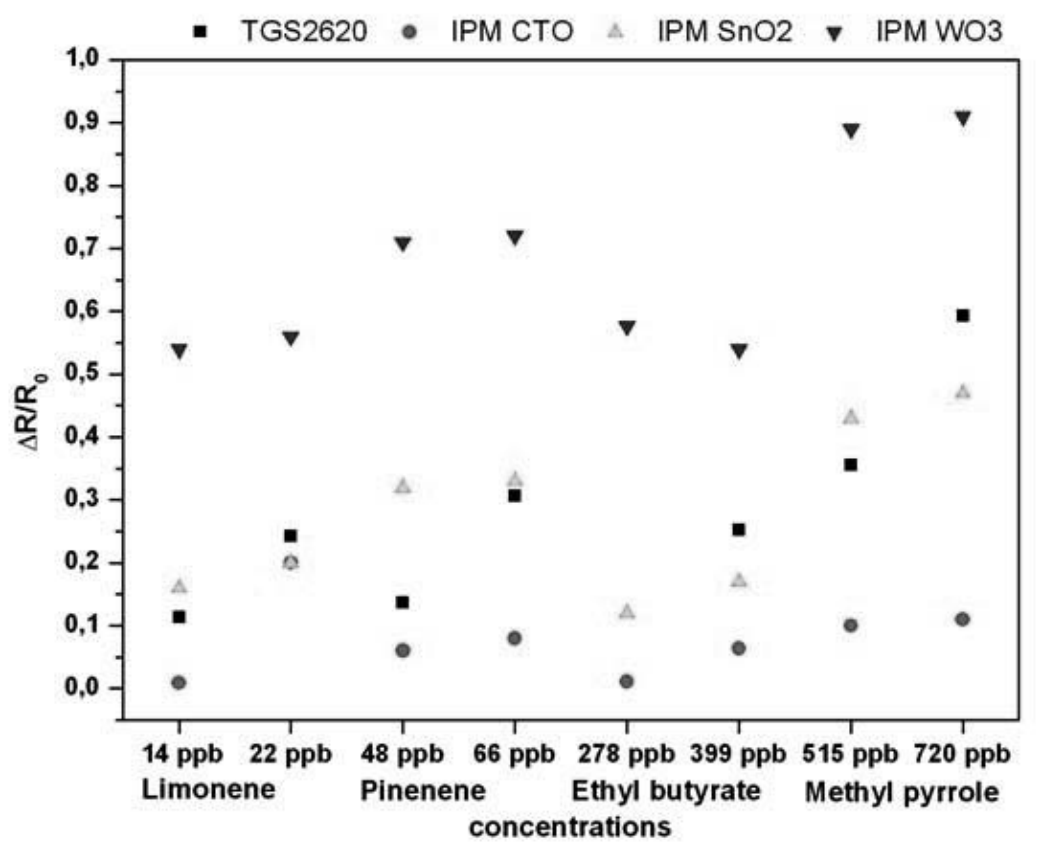

Figure $5 \quad$ Comparison between commercial gas sensors as well as self produced sensors and various aroma concentrations. The operating temperature during the measurements are $325^{\circ} \mathrm{C}$ for Figaro TGS $2620,300^{\circ} \mathrm{C}$ for IPM SnO ${ }_{2}$ and $\mathrm{WO}_{3}$ as well as $450^{\circ} \mathrm{C}$ for IPM CTO.

Futhermore the sensitivity of the developed measurement system is tested with the gas ethylene. Ethylene is a biological hormone which influences fruit ripeness, microbial growth and biological 
senescence. Due to its chemical behaviour it is often used in agricultural and food logistics for controlled fruit ripeness.

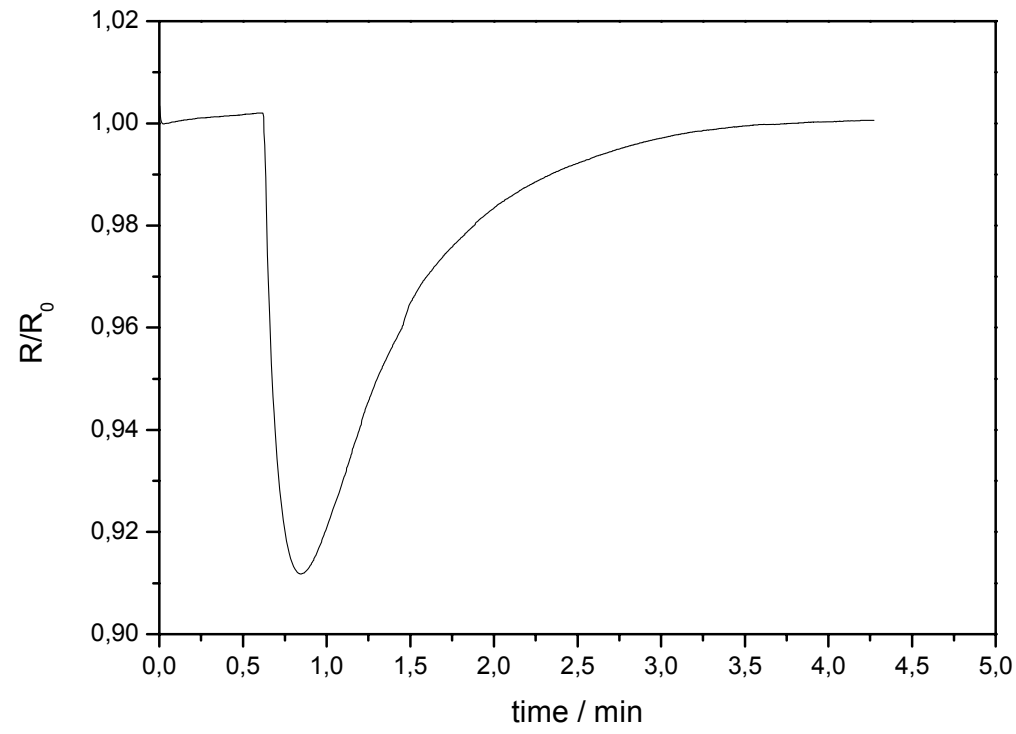

Figure 6 Sensor response of Figaro TGS 2602 to 50ppb ethylene and as a function of the nominal resistance. The operation voltage during the measurement was $5 \mathrm{~V}$.

\section{Conclusion}

The presented measurement system enables reliable and repeatable detection of gas concentrations, down to the ppb-range, as well as assignable to the aromatic flavours. Next to food industry, similar processes in the pharmaceutical area offers further markets for the novel gas chromatographic measurement system.

\section{References}

[1] P. Schieberle, "Quantisation of import roast-smelling odorants in popcorn by stable isotope dilution assay and model studies non flavour formation during popping", Food Chem., 1985, 43

[2] F. Röck, U. Weimar, J. Mitrovics, „Elektronische Nasen und Signalgewinnung“, Technisches Messen, 2007

[3] B. Hivert et.al., "A fast and reproducible method for gas sensor screening to flavour compound", Sensors and Actuators B, 1995, 26

[4] I. Oppermann, M. Bücking, H. Steinhart, „Einfluss von Lagerungsbedingungen auf den Genusswert gelagerter Erdnüsse“, Sensoren und Messsysteme, C.D. Kohl (Ed.), VDE Verlag $\mathrm{GmbH}$, Berlin (2002), 191-194

[5] M. Bücking, I. Oppperman, H. Steinhart, "High Resolution Gas Chromatography - Selective Odorant Measurement by Multisensor Array (HRGC/SOMSA) - Recent Developments", Flavour Research at the Dawn of the Twenty-first Century (Proceedings of the 10th Weurman Flavour Research Symposium 2001), Lavoisier Editions Tec \& Doc, Cachan, France 2003, 524-527

[6] D. Kohl, J. Bock, "Discrimination between untoasted and toasted white bread: an application of the high resolution gas chromatography / selective odorant measurement by multisensor (HRGS / SOMSA)", Proceedings of the Eurosensors XI, 1997

[7] J. Wöllenstein, H. Böttner, J. A. Plaza, C. Cané, Y. Min, H. L. Tuller, „A novel single chip thin film metal oxide array", Sensors and Actuators B: Chemical 93 (1-3) (2003) 350-355

[8] J. Steinhanses, K. Schoene, "Generating vapour mixtures for calibration purpose", Fresenius Zeitschrift für Analytische Chemie, 1989, 557-561 